\title{
Oncologic and Functional Outcomes after Partial Nephrectomy Versus Radical Nephrectomy in T1b Renal Cell Carcinoma: A Multicenter, Matched Case-Control Study in Korean Patients
}

\author{
Hoon Ah Jang, MD, $P h D^{1}$ \\ Jin Wook Kim, MD, PhD² \\ Seok Soo Byun, MD, PhD ${ }^{3}$ \\ Sung Hoo Hong, MD, PhD ${ }^{4}$ \\ Young Jun Kim, MD, PhD 5 \\ Young Hyun Park, MD, PhD ${ }^{4}$ \\ Kyung Suk Yang, PhD ${ }^{6}$ \\ Seok Cho, MD, PhD' \\ Jun Cheon, MD, $P h D^{1}$ \\ Seok Ho Kang, MD, PhD'
}

\author{
${ }^{1}$ Department of Urology, \\ Korea University College of Medicine, Seoul, \\ ${ }^{2}$ Department of Urology, \\ Chung-Ang University College of Medicine, \\ Seoul, ${ }^{3}$ Department of Urology, \\ Seoul National University Bundang Hospital, \\ Seongnam, ${ }^{4}$ Department of Urology, \\ Seoul St. Mary's Hospital, \\ College of Medicine, \\ The Catholic University of Korea, Seoul, \\ ${ }^{5}$ Department of Urology, \\ Chungbuk National University \\ College of Medicine, Cheongju, \\ ${ }^{6}$ Department of Biostatistics, \\ Korea University College of Medicine, \\ Seoul, Korea
}

\section{Purpose}

The study was to compare the oncologic and functional outcomes of partial nephrectomy (PN) and radical nephrectomy (RN) for pathologically proven $\mathrm{T} 1 \mathrm{~b}$ renal cell carcinoma using pair-matched groups.

\section{Materials and Methods}

We reviewed our prospectively maintained database for RN and PN in T1b renal tumors surgically treated between 1999 and 2011 at five institutions in Korea. Of 611 patients treated with PN or RN for a solitary and NX/NO MO renal mass (4-7 cm), 577 (PN, 100; RN, 477 ) patients with pathologically confirmed $\mathrm{pT} 1 \mathrm{~b}$ remained for analysis. Study subjects were grouped by PN or RN, then matched by age, sex, comorbidities, body mass index, tumor size and depth, histologic type, and preoperative estimated glomerular filtration rate (eGFR) using propensities score. To evaluate oncologic outcomes, overall survival (OS), cancer-specific survival (CSS), and progression-free survival (PFS) rates were analyzed. The functional outcomes were evaluated by postoperative eGFR.

\section{Results}

The median follow-up in the RN group was 48.1 and 42.6 months in the PN group. The estimated 10-year CSS rate (PN 85.7\% vs. RN 84.4\%, $p=0.52$ ) and 5- and estimated 10-year PFS rates (PN: $86.4 \%$ and $79.2 \%$ vs. RN: $86.0 \%$ and $66.1 \%, p=0.66$ ) did not differ significantly between groups. The estimated 10 -year OS rate was significantly higher in the PN group (85.7\%) compared to the RN group (73.3\%) ( $p=0.003)$. PN was less likely to induce new-onset chronic kidney disease (CKD) and end-stage CKD compared with RN.

\section{Conclusion}

Our study suggests that patients treated with PN demonstrate a superior OS rate and postoperative renal function with analogous CSS and PFS rates compared with pair-matched patients treated with RN.
Correspondence: Seok Ho Kang, MD, PhD Department of Urology,

Korea University College of Medicine,

73 Inchon-ro, Seongbuk-gu, Seoul 02841, Korea Tel: 82-2-920-6610

Fax: 82-2-928-7864

E-mail: mdksh@korea.ac.kr

Received May 25, 2014

Accepted April 16, 2015

Published Online June 5, 2015

${ }^{*}$ Hoon Ah Jang and Jin Wook Kim contributed equally to this work.
Key words

T1b, Renal cell carcinoma, Partial nephrectomy, Nephron-sparing surgery 


\section{Introduction}

Historically, radical nephrectomy (RN) has been the mainstay treatment for renal cell carcinoma (RCC). Increased incidental detection of small renal masses with the development of radiologic diagnostic tools has brought increased attention to treatment options and operation modality for small renal masses. With the evidence of comparable oncologic outcomes with partial nephrectomy (PN) and the risk of de novo renal failure with RN for a small renal tumor, attention is focused on expanding and setting the indications of PN in small renal tumors. In the last decade, PN has developed rapidly and supplanted $\mathrm{RN}$ as the standard treatment for T1a RCC [1], with comparable oncological outcomes, superior renal function preservation [2] and better quality of life [3]. Although treatment for tumors larger than $4 \mathrm{~cm}$ remains controversial, emerging data indicates that $\mathrm{PN}$ for T1b RCC provides comparable cancer control compared with RN, as well as PN for T1a RCC [4,5]. However, most of those studies are single-center, retrospective and observational studies with low-level evidence, and the results and interpretation are questionable because of uneven distribution of patients and patient selection bias [6]. Therefore, we conducted a pair-matched clinical outcome study in patients who underwent PN or RN for T1b renal tumors. Factors that can affect oncologic and functional outcomes were matched, and data were distributed evenly with regard to age, sex, preoperative renal function, comorbidity, American Society of Anesthesiologists score, body mass index (BMI), tumor size, and histologic subtype.

In this study, we evaluated the oncologic and functional outcomes of PN versus RN in T1b renal tumors within a pairmatched control cohort.

\section{Materials and Methods}

\section{Patient selection and matching}

After approval was obtained from the institutional review board at each center, we retrospectively reviewed our database. We identified 611 patients treated between 1999 and 2011 with RN or PN for a solitary, NX/NO MO solid renal mass $(4-7 \mathrm{~cm})$ at five institutions in Korea. After excluding patients with benign pathology and those with missing records, 577 (PN, 100; RN, 477) patients with pathologically confirmed $\mathrm{pT} 1 \mathrm{~b}$ remained for analysis. Patients who underwent PN $(n=100)$ were matched to patients who underwent RN (n=458).
To eliminate the influence of the confounding factors and achieve equal distributions of patients between the two groups, we pair-matched the patients of the two groups using propensity scores. The propensity score included age, sex, comorbidities (hypertension, diabetes), BMI, tumor size and depth, histologic type, and preoperative estimated glomerular filtration rate (eGFR). Preoperative eGFR was classified into five groups according to the current guidelines for chronic kidney disease (CKD) [7].

Clinical data including age, sex, BMI, tumor size and location, and surgical approach were recorded. Intraoperative and postoperative data including operative time, estimated blood loss (EBL), intraoperative transfusions and serum creatinine and hemoglobin levels on postoperative day 1 were recorded. Complication rates, tumor recurrences, overall survival (OS) rate, cancer-specific survival (CSS) rate, progression-free survival (PFS) rate, and renal function outcomes were documented. The OS, CSS, and PFS rates were measured until the last date of follow-up. The modified Clavien classification system was used to report complications [8].

\section{Patient follow-up and renal function evaluation}

Patients were evaluated for postoperative recurrence by chest X-ray and computed tomography scan every 6 months for the first 3 years. After that period, follow-up evaluations were performed annually.

Renal function evaluation included serum creatinine and eGFR on preoperative, one day and 3 months postoperative and annually thereafter. The eGFR was calculated for each creatinine value based on the Cockcroft-Gault equation [9]. Postoperative new-onset CKD was defined as eGFR lower than $60 \mathrm{~mL} / \mathrm{min} / 1.73 \mathrm{~m}^{2}$, according to the National Kidney Foundation Dialysis Outcomes Quality Initiative Clinical Practice Guidelines [10].

\section{Surgical approach and technique}

Procedures performed included pure laparoscopic, handassisted laparoscopic, robot-assisted laparoscopic and open RN and PN. Surgical modality and approach were decided by surgeon preference and tumor characteristics. All surgeries were performed by skilled surgeons using standard methods.

\section{Statistical analysis}

Analysis used SPSS ver. 13.0 (SPSS Inc., Chicago, IL). The data are presented as the mean and range. Clinical and pathological variables were compared between patients who underwent PN and $\mathrm{RN}$ using the chi-square test and 
Table 1. Partial nephrectomy versus radical nephrectomy: clinical, surgical, and pathologic parameters

\begin{tabular}{|c|c|c|c|}
\hline Parameter & PN & RN & p-value \\
\hline No. of patients & 100 & 100 & \\
\hline No. of women & 29 & 29 & $>0.99$ \\
\hline Age at operation (yr) & $55.3(26$ to 80$)$ & 55.7 (31 to 81$)$ & 0.80 \\
\hline BMI $\left(\mathrm{kg} / \mathrm{m}^{2}\right)$ & $24.3(19.5$ to 38.1$)$ & $24.8(17.3$ to 36.6$)$ & 0.68 \\
\hline ECOG $3+4(\%)$ & 5 & 3 & 0.13 \\
\hline Patients with diabetes & 9 & 17 & 0.09 \\
\hline Patients with hypertension & 34 & 39 & 0.46 \\
\hline Preoperative creatinine $(\mathrm{mg} / \mathrm{dL})$ & $1.0(0.4$ to 2.0$)$ & $1.0(0.6$ to 1.6$)$ & 0.28 \\
\hline Preoperative eGFR (mL/min/1.73 m²) & $80.5(27.8$ to 193.5$)$ & 88.8 (7.4 to 186.6$)$ & 0.41 \\
\hline $\begin{array}{l}\text { Preoperative eGFR }\left(\mathrm{mL} / \mathrm{min} / 1.73 \mathrm{~m}^{2}\right) \text { : } \\
\geq 90 / 89-60 / 59-30 / 29-15 /<15\end{array}$ & $31 / 47 / 21 / 1 / 0$ & $29 / 47 / 23 / 0 / 1$ & 0.70 \\
\hline Operative time & 182.2 (60 to 450$)$ & 190.0 (75 to 393$)$ & 0.39 \\
\hline EBL & $290.0(20$ to 1,800$)$ & 306.4 (10 to 1,200$)$ & 0.63 \\
\hline Change in $\mathrm{Hb}$ preoperative to nadir & $1.3(-3.2$ to 6.1$)$ & $1.8(-3.8$ to 7.9$)$ & 0.16 \\
\hline Received transfusions & 14 & 14 & $>0.99$ \\
\hline Intraoperative complications & 7 & 5 & 0.42 \\
\hline Postoperative complications & 8 & 6 & 0.09 \\
\hline $\operatorname{PSM}(\%)$ & 3 & NA & \\
\hline Pathologic tumor size $(\mathrm{cm})$ & $4.9(4.0$ to 6.7$)$ & $4.9(4.0$ to 6.9$)$ & 0.98 \\
\hline \multicolumn{4}{|l|}{ Pathology } \\
\hline Clear-cell & 78 & 77 & 0.30 \\
\hline Papillary & 8 & 11 & \\
\hline Chromophobe & 7 & 7 & \\
\hline Mixed or other & 7 & 5 & \\
\hline
\end{tabular}

Values are presented as mean (range) or number (\%). PN, partial nephrectomy; RN, radical nephrectomy; BMI, body mass index; ECOG, Eastern Cooperative Oncology Group; eGFR, estimated glomerular filtration rate; EBL, estimated blood loss; $\mathrm{Hb}$, hemoglobin; PSM, positive surgical margin; NA, not applicable.

Student's $t$ test as appropriate. The OS, CSS, PFS, and new-onset CKD rates were analyzed using the Kaplan-Meier method. Post operative renal functions between groups were compared as the mean percent of decline in eGFR from baselines at postoperative $3,12,24,36$, and 48 months by Student's $t$ test. To compare the survival rate between groups, the log-rank test was used. A Cox proportional hazards model was then used to compare the OS, CSS and PFS rates of patients who underwent PN as opposed to RN. The associations between variables and the outcome parameters are presented with the hazard ratios and $95 \%$ confidence intervals. Null hypotheses of no difference were rejected if p-values were less than 0.05 , or, equivalently, if the $95 \%$ confidence intervals (CIs) of hazard ratio estimates excluded 1 .

\section{Results}

\section{Patient and tumor characteristics}

Patient demographics and surgical and perioperative data from both groups are summarized in Table 1. The two groups were similar in age, sex, BMI, and number and type of comorbidity. Preoperative mean creatinine and eGFR were similar between the groups: $0.98 \mathrm{PN}$ (range, 0.4 to 2.0) and $1.04 \mathrm{RN}$ (range, 0.62 to 1.75 ) ( $\mathrm{p}=0.28$ ), $80.46 \mathrm{PN}$ (range, 24.5 to 177.7$)$, and $88.79 \mathrm{RN}$ (range, 24.9 to 192.0$)(\mathrm{p}=0.41)$, respectively.

Tumor characteristics are also shown in Table 1. The mean pathologic tumor size was similar between the two groups: $4.90 \mathrm{~cm} \mathrm{PN}$ and $4.91 \mathrm{~cm} \mathrm{RN} \mathrm{(} \mathrm{p}=0.98$ ). The ratio of the pathological variables was also similar between the two groups $(\mathrm{p}=0.3)$.

Laparoscopic surgery was performed in 130 patients. Among them, 64 patients underwent pure laparoscopic 
Table 2. Intraoperative and postoperative complications

\begin{tabular}{|c|c|c|c|}
\hline Complication & $\mathbf{P N}$ & $\mathbf{R N}$ & Clavien-Dindo grade \\
\hline \multicolumn{4}{|l|}{ Intraoperative complication } \\
\hline Organ injury & $3^{\text {a) }}$ & $2^{\mathrm{b})}$ & - \\
\hline Pleura injury & 4 & 3 & - \\
\hline \multicolumn{4}{|l|}{ Postoperative complication } \\
\hline Wound infection & 1 & 1 & I \\
\hline Prolonged ileus & 1 & 1 & I \\
\hline Urine retention & 1 & - & I \\
\hline Incisional hernia not necessitating intervention & 2 & 2 & I \\
\hline Acute renal failure & 2 & 2 & II \\
\hline Urine leakage & 1 & - & IIIa \\
\hline
\end{tabular}

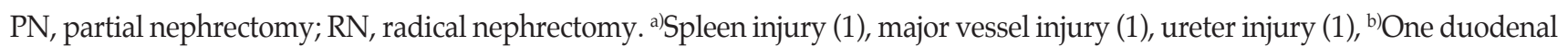
injury, major vessel injury (1).

surgery (PN, n=37; RN, n=27), 14 patients underwent handassisted laparoscopic surgery ( $P N, n=1 ; R N, n=13)$, and 52 patients underwent robot-assisted laparoscopic surgery (PN, $\mathrm{n}=18 ; \mathrm{RN}, \mathrm{n}=34$ ). Open surgery was performed in 70 patients (PN, n=44; RN, n=26).

\section{Perioperative and postoperative complications}

Perioperative parameters including mean operative time, EBL and transfusion rate between the two groups did not differ significantly $(p>0.05)$. The mean change in preoperative hemoglobin $(\mathrm{Hb})$ to postoperative $\mathrm{Hb}$ was similar between groups $(\mathrm{p}=0.16)$. Renal pedicle clamping was conducted only in the PN group, in 96 patients (warm ischemia, $\mathrm{n}=82$; cold ischemia, $\mathrm{n}=14$ ), and the mean ischemic time was 29.97 minutes (range, 9 to 68 minutes).

A summary of all complications is shown in Table 2 . The overall complication rate was similar between groups $(\mathrm{p}>0.05)$. Intraoperative complications in the PN group consisted of three organ injuries (one spleen injury, one major vessel injury, and one ureter injury) and four pleural injuries. In the RN group, there were two organ injuries (one major vessel injury and one duodenal injury) and three pleural injuries. The postoperative complication rate was comparable in patients treated with PN and RN ( $p=0.09$ ). Postoperative complications for PN included five patients with grade I, two patients with grade II, and one patient with grade IIIa complications. In the RN group, there were four cases of grade I and two cases of grade II postoperative complications.

In the PN group, three patients had a positive surgical margin (PSM), and of those, two were treated laparoscopically and one treated with open PN.

\section{Tumor progression and survival}

The median follow-up duration in the RN group was 48.1 and 42.6 months for the PN group.

Tumor progression was found in six of 100 patients after PN. Of those, three patients developed local recurrence and three patients developed distant metastases after a median duration of 97.0 months (95\% CI, 85.05 to 109.04 months). In the PN group, three patients had a PSM, and none of these developed local or distant recurrence after a median followup of 37 months (range, 19 to 45 months). In the RN group, 12 of 100 patients developed distant metastases after a median of 110.7 months (95\% CI, 98.54 to 123.00 months). The PFS rate was comparable between the two groups (log-rank, $\mathrm{p}=0.66)$. The 5- and 10-year PFS rates were $86.4 \%$ and $79.2 \%$ for the PN group and $86.0 \%$ and $66.0 \%$ in the RN group, respectively (Table 3, Fig. 1).

The CSS rates for patients with T1b RCC treated with PN or RN were comparable (log-rank, $\mathrm{p}=0.52$ ) (Table 3 ). In the PN group, one patient died of RCC at 83 months after surgery. After RN, four patients died of RCC at a median of 110.4 months. The estimated 10-year CSS rate for PN was $85.7 \%$, similar to the RN rate of $84.4 \%$. The Cox proportional hazards model adjusting for propensity scores also did not differ in CSS rate between groups (hazard ratio [HR], 2.01; 95\% CI, 0.22 to 18.33 ).

The estimated 10-year OS rate was significantly higher in the PN group $(85.7 \%)$ than the $\mathrm{RN}$ group $(73.3 \%)$ in the Kaplan-Meier analysis (log-rank, $\mathrm{p}=0.003$ ). Using the Cox proportional hazards model, tumor size $(\mathrm{p}=0.947)$, type of surgery $(p=0.131)$, and postoperative renal function $(p=0.146)$ were not significantly associated with OS. 
Table 3. Oncologic outcomes

\begin{tabular}{|c|c|c|c|}
\hline Parameter & PN & $\mathbf{R N}$ & p-value \\
\hline \multicolumn{4}{|l|}{ Follow-up (mo) } \\
\hline Median & 48.1 & 42.6 & 0.29 \\
\hline Range & $6-116$ & $3-140$ & \\
\hline Positive margins $(\%)$ & 3 & NA & \\
\hline \multicolumn{4}{|l|}{ PFS rate } \\
\hline 5 -Year $(\%)$ & 86.4 & 86.0 & 0.66 \\
\hline 10 -Year $(\%)$ & 79.2 & 66.0 & \\
\hline Time to recurrence, median $(95 \% \mathrm{CI}, \mathrm{mo})$ & $97(85.1-109.0)$ & $110.7(98.5-123.0)$ & \\
\hline \multicolumn{4}{|l|}{ CSS rate } \\
\hline 10 -Year $(\%)$ & 85.7 & 84.4 & 0.52 \\
\hline Duration of CSS, median (95\% CI, mo) & $110.4(102.1-118.7)$ & $129.0(119.4-138.6)$ & \\
\hline \multicolumn{4}{|l|}{ OS rate } \\
\hline 10 -Year $(\%)$ & 85.7 & 73.3 & 0.003 \\
\hline Duration of OS, median $(95 \% \mathrm{CI}, \mathrm{mo})$ & $110(102.1-118.7)$ & $117.8(106.2-129.5)$ & \\
\hline
\end{tabular}

PN, partial nephrectomy; RN, radical nephrectomy; NA, not applicable; PFS, progression-free survival; CSS, cancer-specific survival; OS, overall survival.

\section{Change in renal function}

Forty-six patients (PN, 22; RN, 24) had pre-existing CKD before surgery. There was no difference in baseline eGFR between PN and $R N(p=0.41)$. Renal function declined in both groups from preoperative to 3 months postoperative (80.46; range, 24.5 to 177.7 ) to $71.99 \mathrm{~mL} / \mathrm{min} / 1.73 \mathrm{~m}^{2}$ (range, 9.6 to $172.3 \mathrm{~mL} / \mathrm{min} / 1.73 \mathrm{~m}^{2}$ ) and $88.79 \mathrm{~mL} / \mathrm{min} / 1.73 \mathrm{~m}^{2}$ (range, 24.9 to $192.0 \mathrm{~mL} / \mathrm{min} / 1.73 \mathrm{~m}^{2}$ ) to 59.27 (range, 29.8 to 137.4) in the PN and RN groups, respectively). Changes in renal function in both groups are summarized in Fig. 2. The mean percent decline of eGFR from baseline to postoperative $3,12,24,36$, and 48 months were all greater in the RN group compared to the PN group $(\mathrm{p}<0.05)$. New-onset CKD (eGFR $<60 \mathrm{~mL} / \mathrm{min} / 1.73 \mathrm{~m}^{2}$ ) occurred more frequently in the RN group $(\mathrm{n}=27)$ than in the PN group $(\mathrm{n}=5)(\mathrm{p}=0.00 ; \mathrm{HR}, 11.83$; 95\% CI, 4.09 to 34.20) (Fig. 3). The ratio of new-onset CKD increased as end-stage CKD $\left(\mathrm{eGFR}<15 \mathrm{~mL} / \mathrm{min} / 1.73 \mathrm{~m}^{2}\right)$ occurred in only one patient who underwent $\mathrm{PN}$ and in no patients in the RN group ( $\mathrm{p}>0.99$ ).

\section{Discussion}

Our results with T1b RCC demonstrated comparable 5- and estimated 10-year PFS and estimated 10-year CSS rates and superior estimated 10-year OS for patients treated with PN versus RN. Five- and estimated 10-year PFS rates were
$86.4 \% / 79.2 \%$ for PN and $86.0 \% / 66.0 \%$ for RN. Estimated 10-year CSS rate was $85.7 \%$ for PN and $84.4 \%$ for RN. As the tendency changes toward performing more $\mathrm{PN}$ procedures for T1b RCC, studies demonstrate that the oncologic outcome and survival rate are comparable in patients treated with PN compared with RN. Leibovich et al. [11] reported that PN led to higher 5-year CSS and 5-year tumor recurrence rates compared to RN in 4 to $7 \mathrm{~cm}$ RCC using univariate analysis. Similarly, Thompson et al. [5] found no significant difference in 5- and 10-year CSS rates in patients with $\mathrm{T} 1 \mathrm{~b}$ who underwent PN or RN, although there was a tendency for a high rate of solitary kidney or CKD in the PN group, implying the possibility of patient selection bias. Badalato et al. [12] reported that there was no significant difference in the 5-year CSS rate in patients with T1b RCC treated with PN versus RN (82.5\% and 85\%, $\mathrm{p}=0.161$, respectively). Based on these reports and the results of the present study, we suggest that $\mathrm{PN}$ is oncologically safe and has comparable, at least not inferior outcomes, compared with $\mathrm{RN}$ for the treatment of T1b RCC.

A major benefit of $\mathrm{PN}$ is renal function preservation and the derived potential positive effects on OS and quality of life [5]. Weight et al. [13] reported that a postoperative decline in GFR of $16.6 \%$ and $23.5 \%$ was observed in patients treated with PN and RN for T1b RCC, respectively. lizuka et al. [14] reported that PN for CT1b resulted in a similar postoperative eGFR level to that of cT1a. In addition, the probability of freedom from the new onset of CKD after PN did not differ between $\mathrm{CT} 1 \mathrm{~b}$ or cT1a tumors. In our study, renal function, estimated by eGFR, decreased after both PN and 


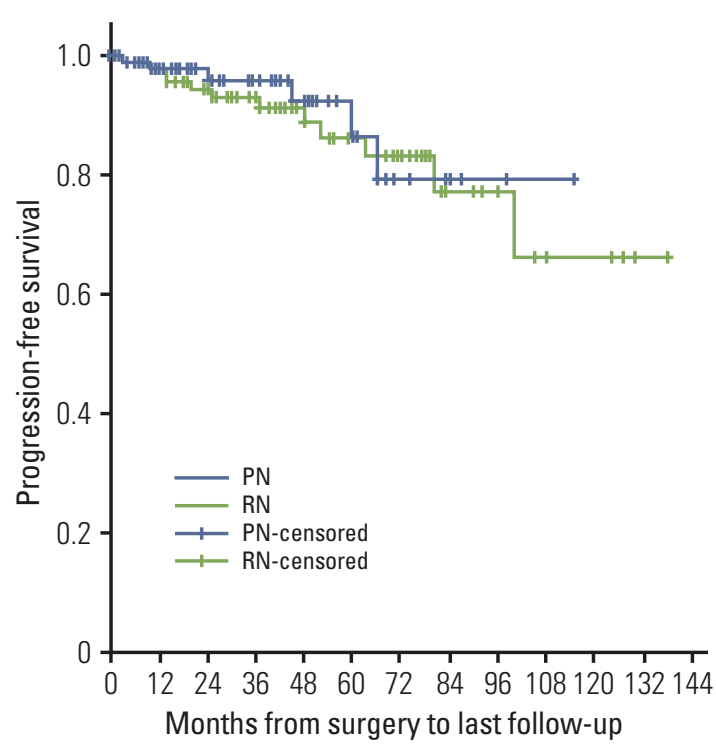

A

B
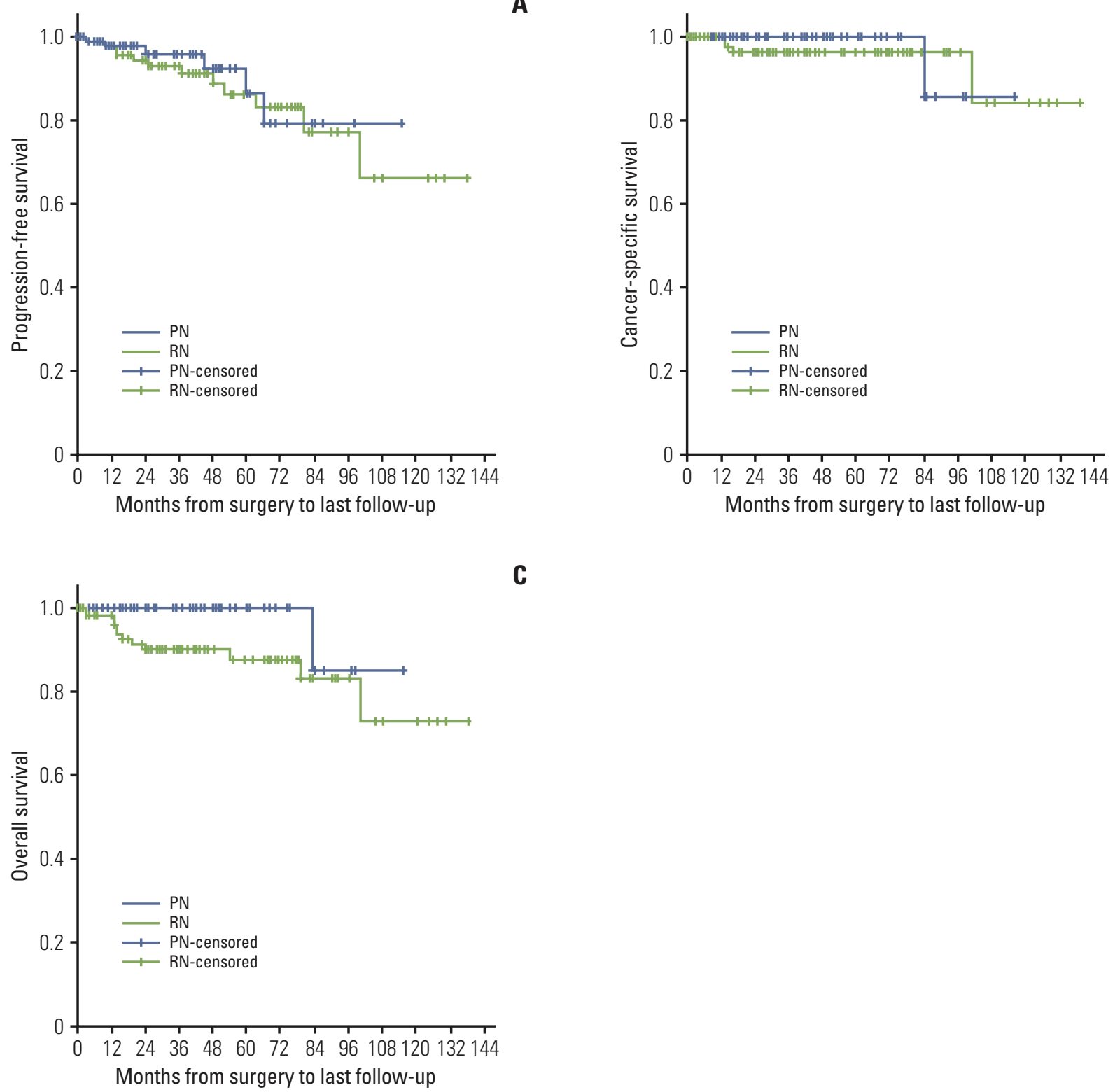

Fig. 1. Kaplan-Meier analysis of progression-free survival (A), cancer-specific survival (B), and overall survival (C) for 200 patients after partial nephrectomy (PN) or radical nephrectomy $(\mathrm{RN})$ for $\mathrm{T} 1 \mathrm{~b}$ renal cell carcinoma. Comparison of survival analysis performed using the log-rank test.

$\mathrm{RN}$, but PN led to better postoperative renal function preservation compared to RN. The change in eGFR from baseline to 3 months and 4 years was $10.52 \% / 8.04 \%$ for PN and $33.24 \% / 35.12 \%$ for RN. PN was less likely to induce newonset CKD and end-stage CKD compared with RN. The present study demonstrates the feasibility and validity of PN for T1b RCC with respect to oncologic outcome and superior renal function preservation.
In the present study, renal function decreased sharply during the first 3 months after PN and RN and was maintained for 4 years. The percent decline of eGFR from baseline to postoperative follow-up time was significantly smaller in the patients treated with PN compared with RN. Although technical concerns relative to the effect of renal artery occlusion or reperfusion injury and warm ischemia, and the association of resection volume and remnant renal function in 


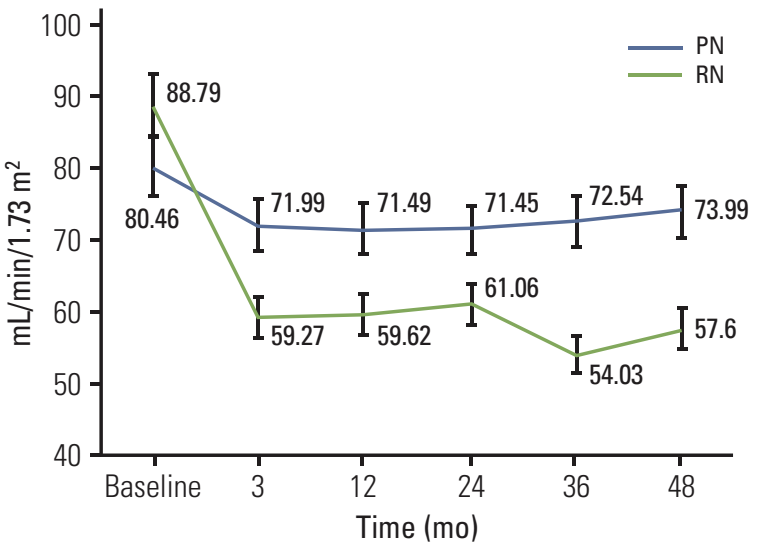

\begin{tabular}{|c|c|c|c|c|c|c|}
\hline & Baseline & $3 \mathrm{mo}$ & $12 \mathrm{mo}$ & $24 \mathrm{mo}$ & $36 \mathrm{mo}$ & $48 \mathrm{mo}$ \\
\hline \multicolumn{7}{|l|}{ PN } \\
\hline Mean & 80.5 & 72.0 & 71.5 & 71.5 & 72.5 & 74.0 \\
\hline SD & 28.5 & 32.4 & 24.4 & 21.7 & 20.5 & 23.9 \\
\hline $\begin{array}{l}\text { Change from } \\
\text { baseline (\%) }\end{array}$ & & 10.5 & 11.1 & 11.2 & 9.8 & 8.0 \\
\hline \multicolumn{7}{|l|}{$\mathrm{RN}$} \\
\hline Mean & 88.8 & 59.3 & 59.6 & 61.1 & 54.0 & 57.6 \\
\hline SD & 96.7 & 24.5 & 27.1 & 21.3 & 16.6 & 20.5 \\
\hline $\begin{array}{l}\text { Change from } \\
\text { baseline (\%) }\end{array}$ & & 33.2 & 32.9 & 31.2 & 39.1 & 35.1 \\
\hline p-value & 0.41 & 0.04 & 0.02 & 0.03 & 0.00 & 0.03 \\
\hline
\end{tabular}

Fig. 2. Comparison of renal function from baseline to 4-year follow-up. PN, partial nephrectomy; RN, radical nephrectomy; SD, standard deviation.

T1b RCC require additional consideration and investigation, it seems clear that the functional outcome after PN is superior to that after RN in patients with T1b RCC.

Another impact of postoperative renal function preservation is on cardiovascular risk and OS. Several studies $[13,15]$ show an advantage in OS for patients who underwent PN, mainly attributed to the renal function preservation after surgery. However, in a randomized trial by van Poppel et al. [16], 10-year OS was greater in patients treated with RN $(81.1 \%)$ than in patients treated with PN $(75.7 \%)(p=0.03)$. They criticized the superior outcome of PN in other studies, saying those results depend heavily on patient selection. In the present study, postoperative renal function manifested as eGFR was better preserved in the PN group, and the RN group had more frequent new-onset postoperative CKD. The OS rate was significantly higher in the PN group compared with the RN group ( $p=0.003$ ). While our study, in design, may also fundamentally present results of careful patient selection when choosing candidates for PN, neither has our study shown that renal function following RN or PN signif-

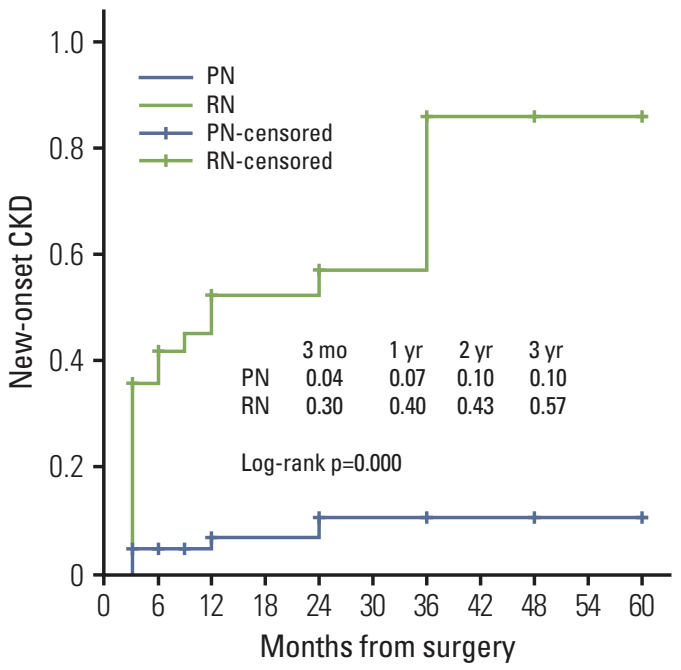

Fig. 3. Kaplan-Meier estimates of new-onset chronic kidney disease (CKD) rate for patients after partial nephrectomy (PN) or radical nephrectomy (RN) for T1b renal cell carcinoma.

icantly affected OS. While we hypothesized that postoperative renal function may prognosticate OS, in multivariate Cox regression analysis, postoperative eGFR was not associated with OS, despite a significant higher ratio of new-onset of CKD in the RN group than the PN group. Also, there was no significant prognostic factor for OS using the multivariate Cox regression analysis.

The critical opinions and concerns of PN for RCC include multifocality and microscopic satellite of RCC and incomplete tumor resection. Multifocality is a characteristic of RCC and occurs in approximately $16 \%$ [17] and 47\% [18] of RCC patients in the form of a satellite lesion. However, the local recurrence rate after PN for T1b RCC was $1 \%$ to $5.4 \%$ $[7,19,20]$, lower than the high rate of multifocality or microscopic satellite tumor lesions. Since the local recurrence rate of PN for T1a RCC is $0 \%-10 \%$ [2,21], we suggest no significant increase in T1b RCC. Iizuka et al. [14] reported that, after PN for T1a and T1b RCC, local recurrence rates were comparable, $5 \%$ and $1 \%$, respectively $(\mathrm{p}=0.57)$. In the present study, the local recurrence rate was $3 \%$, similar to other studies.

PN for larger renal tumors can be technically challenging and requires extensive experience, causing concerns of higher perioperative complications and incomplete tumor resection. The risk of perioperative complications with $\mathrm{PN}$ is slightly higher than with RN. In a prospective, randomized study, van Poppel et al. [16] reported that PN is associated with increased hemorrhage (3.1\% and $1.2 \%)$, urinary fistula 
( $4.4 \%$ and $0 \%, \mathrm{p}<0.001)$ and re-operation due to side effects (4.4\% and 2.4\%). In the present study, there was no significant difference in mean operative time, EBL or transfusion rate, and the overall intraoperative complication rate was similar between the groups.

Several studies have reported equivalent complication rates between the $\mathrm{PN}$ and $\mathrm{RN}$ groups $[6,16]$. It has also been suggested that complications of PN are minimized with increasing experience $[22,23]$. The association of the PSM rate and tumor size is still under debate. Generally, PSM is suggested to increase with increasing tumor size. However, Patard et al. [4] reported that the PSM rate was comparable in small tumors and tumors larger than $4 \mathrm{~cm}$. PSM after PN for T1b RCC occurs in $0 \%-13.3 \%[13,24]$ of cases. Whether or not PSM is a risk factor for tumor recurrence after PN, which is still controversial, its impact on survival is limited [6,12]. Yossepowitch et al. [25] reported that patients with PSM after PN were not at increased risk for local recurrence or metastasis after a mean follow-up time of 3.4 years. PSM rates after PN are reported differ by surgical approach and tend to increase in minimally-invasive approaches $(0.7 \%-4 \%$ in laparoscopic approach, 3.9\%-5.7\% in robot-assisted approach) compared to an open approach $(0 \%-7 \%)[4,23]$. In the present study, PSM was 3\%, and none of the patients developed local or distant recurrence after a median followup of 37 months (19-45 months).

Since RN was established as a surgical treatment for RCC, it has been the standard of care in treating RCC. During the last decade, many urologic surgeons have been cautiously performing PN for small renal tumors. Although the cutoff of $4 \mathrm{~cm}$ in the treatment of RCC generated controversy after T1 substratification was introduced in 2002, it has been validated by a number of studies showing differences between T1a and T1b RCC in a 5-year CSS. However, emerging data about PN for T1b RCC indicate that PN provides cancer control and survival comparable to RN $[4,5]$. The present study is valuable in that it adds the evidence of feasibility of $\mathrm{PN}$ for T1b RCC based on data that is evenly pair-matched and includes both basic patient characteristics and tumor characteristics. Also, in the present study, both oncologic and functional outcomes were simultaneously compared between PN and RN. It is important to evaluate the benefit of OS in the patients treated with PN.

There are still several limitations of this study. Although we conducted a pair-matched study and the data were distributed evenly with regard to patient and tumor characteristics, it was nevertheless a retrospective design. To overcome the disadvantages of a retrospective study, patient inclusion was tailored by propensity score matching. This method is suggested as a way to overcome the effects of observed covariates and allowing focus on the treatment method. Through propensity score matching, studies may overcome the difficulties of conducting large randomized prospective studies where covariates other than the purposed outcome cannot be manipulated, and thus may introduce new bias if the sample size is not sufficiently large. However, propensity score matching has its failings, as it cannot compensate for unobserved covariates such as, in our study, the lack of cause of death (except death from RCC) and occurrence of cardiovascular events. Unidentified potential confounders may have resulted in some early cases of RN showing significant change on survival.

\section{Conclusion}

Our study suggests that PN shows similar CSS and PFS compared with RN in T1b RCC in a pair-matched clinical outcomes study. Furthermore, PN shows benefits in preservation of postoperative renal function and OS. Though there are several limitations of the present study, our results suggest additional support for the feasibility of PN in T1b renal tumors. A large-scale prospective study is needed to clarify the association of OS and postoperative renal function.

\section{Conflicts of Interest}

Conflict of interest relevant to this article was not reported.

\section{Acknowledgments}

This study was supported by a research grant from Korea University Medical College (Seoul, Korea). 


\section{References}

1. Van Poppel H, Dilen K, Baert L. Incidental renal cell carcinoma and nephron sparing surgery. Curr Opin Urol. 2001;11:281-6.

2. Lee CT, Katz J, Shi W, Thaler HT, Reuter VE, Russo P. Surgical management of renal tumors $4 \mathrm{~cm}$ or less in a contemporary cohort. J Urol. 2000;163:730-6.

3. Clark PE, Schover LR, Uzzo RG, Hafez KS, Rybicki LA, Novick AC. Quality of life and psychological adaptation after surgical treatment for localized renal cell carcinoma: impact of the amount of remaining renal tissue. Urology. 2001;57:252-6.

4. Patard JJ, Pantuck AJ, Crepel M, Lam JS, Bellec L, Albouy B, et al. Morbidity and clinical outcome of nephron-sparing surgery in relation to tumour size and indication. Eur Urol. 2007;52:148-54.

5. Thompson RH, Siddiqui S, Lohse CM, Leibovich BC, Russo P, Blute ML. Partial versus radical nephrectomy for 4 to $7 \mathrm{~cm}$ renal cortical tumors. J Urol. 2009;182:2601-6.

6. Campbell SC, Novick AC. Expanding the indications for elective partial nephrectomy: is this advisable? Eur Urol. 2006;49: 952-4.

7. National Kidney Foundation. K/DOQI clinical practice guidelines for chronic kidney disease: evaluation, classification, and stratification. Am J Kidney Dis. 2002;39(2 Suppl 1):S1-266.

8. Dindo D, Demartines N, Clavien PA. Classification of surgical complications: a new proposal with evaluation in a cohort of 6336 patients and results of a survey. Ann Surg. 2004;240:20513.

9. Cockcroft DW, Gault MH. Prediction of creatinine clearance from serum creatinine. Nephron. 1976;16:31-41.

10. Levey AS, Coresh J, Balk E, Kausz AT, Levin A, Steffes MW, et al. National Kidney Foundation practice guidelines for chronic kidney disease: evaluation, classification, and stratification. Ann Intern Med. 2003;139:137-47.

11. Leibovich BC, Blute M, Cheville JC, Lohse CM, Weaver AL, Zincke $\mathrm{H}$. Nephron sparing surgery for appropriately selected renal cell carcinoma between 4 and $7 \mathrm{~cm}$ results in outcome similar to radical nephrectomy. J Urol. 2004;171:1066-70.

12. Badalato GM, Kates M, Wisnivesky JP, Choudhury AR, McKiernan JM. Survival after partial and radical nephrectomy for the treatment of stage T1bN0M0 renal cell carcinoma (RCC) in the USA: a propensity scoring approach. BJU Int. 2012;109: 1457-62.

13. Weight CJ, Lieser G, Larson BT, Gao T, Lane BR, Campbell SC, et al. Partial nephrectomy is associated with improved overall survival compared to radical nephrectomy in patients with unanticipated benign renal tumours. Eur Urol. 2010;58:293-8.

14. Iizuka J, Kondo T, Hashimoto Y, Kobayashi H, Ikezawa E, Takagi T, et al. Similar functional outcomes after partial nephrectomy for clinical $\mathrm{T} 1 \mathrm{~b}$ and $\mathrm{T} 1 \mathrm{a}$ renal cell carcinoma. Int
J Urol. 2012;19:980-6.

15. Kim SP, Murad MH, Thompson RH, Boorjian SA, Weight CJ, Han LC, et al. Comparative effectiveness for survival and renal function of partial and radical nephrectomy for localized renal tumors: a systematic review and meta-analysis. J Urol. 2012 Oct 18 [Epub]. http://dx.doi.org/10.1016/j.juro.2012.10.026.

16. Van Poppel H, Da Pozzo L, Albrecht W, Matveev V, Bono A, Borkowski A, et al. A prospective, randomised EORTC intergroup phase 3 study comparing the oncologic outcome of elective nephron-sparing surgery and radical nephrectomy for low-stage renal cell carcinoma. Eur Urol. 2011;59:543-52.

17. Kletscher BA, Qian J, Bostwick DG, Andrews PE, Zincke H. Prospective analysis of multifocality in renal cell carcinoma: influence of histological pattern, grade, number, size, volume and deoxyribonucleic acid ploidy. J Urol. 1995;153(3 Pt 2): 904-6.

18. Kobayashi M, Hashimoto S, Tokue A. Nephron-sparing surgery is still controversial for patients with renal cell carcinoma and normal contralateral kidney: risks predictable by AgNOR counts in satellite lesions. Mol Urol. 2000;4:21-9.

19. Roos FC, Brenner W, Muller M, Schubert C, Jager WJ, Thuroff JW, et al. Oncologic long-term outcome of elective nephronsparing surgery versus radical nephrectomy in patients with renal cell carcinoma stage $\mathrm{pT} 1 \mathrm{~b}$ or greater in a matched-pair cohort. Urology. 2011;77:803-8.

20. Lane BR, Campbell SC, Gill IS. 10-year oncologic outcomes after laparoscopic and open partial nephrectomy. J Urol. 2013;190:44-9.

21. Hafez KS, Fergany AF, Novick AC. Nephron sparing surgery for localized renal cell carcinoma: impact of tumor size on patient survival, tumor recurrence and TNM staging. J Urol. 1999;162:1930-3.

22. Thompson RH, Leibovich BC, Lohse CM, Zincke H, Blute ML. Complications of contemporary open nephron sparing surgery: a single institution experience. J Urol. 2005;174:855-8.

23. Gill IS, Matin SF, Desai MM, Kaouk JH, Steinberg A, Mascha E, et al. Comparative analysis of laparoscopic versus open partial nephrectomy for renal tumors in 200 patients. J Urol. 2003;170:64-8.

24. Papalia R, Simone G, Ferriero M, Guaglianone S, Costantini M, Giannarelli D, et al. Laparoscopic and robotic partial nephrectomy without renal ischaemia for tumours larger than $4 \mathrm{~cm}$ : perioperative and functional outcomes. World J Urol. 2012;30:671-6.

25. Yossepowitch O, Thompson RH, Leibovich BC, Eggener SE, Pettus JA, Kwon ED, et al. Positive surgical margins at partial nephrectomy: predictors and oncological outcomes. J Urol. 2008;179:2158-63. 